OPEN ACCESS

Edited by:

Bin Mu,

Lanzhou Institute of Chemical Physics (CAS), China

Reviewed by: Jing Ouyang,

Central South University, China Jianxi Zhu,

Guangzhou Institute of Geochemistry, (CAS), China

*Correspondence:

Zepeng Zhang unite508@163.com

Specialty section:

This article was submitted to Green and Sustainable Chemistry, a section of the journal Frontiers in Chemistry

Received: 06 June 2021

Accepted: 26 July 2021 Published: 25 August 2021

Citation: Chen H, Geng J, Zhang Z, Jiang $R$,

Zhai J and Zhang J (2021) The Structure and Properties of Sepiolite with Partial Lattice Ions Substituted by Aluminum lons.

Front. Chem. 9:721225.

doi: 10.3389/fchem.2021.721225

\section{The Structure and Properties of Sepiolite with Partial Lattice lons Substituted by Aluminum Ions}

\author{
Huiwen Chen ${ }^{1}$, Junming Geng ${ }^{2}$, Zepeng Zhang ${ }^{1 *}$, Rui Jiang ${ }^{1}$, Jingya Zhai ${ }^{1}$ and \\ Jinchuan Zhang ${ }^{3}$
}

${ }^{1}$ Beijing Key Laboratory of Materials Utilization of Nonmetallic Minerals and Solid Wastes, National Laboratory of Mineral Materials, School of Materials Science and Technology, China University of Geosciences, Beijing, China, ${ }^{2}$ National Engineering Technology Research Center of Flame Retardant Materials, School of Materials, Beijing Institute of Technology, Beijing, China, ${ }^{3}$ School of Energy Resources, China University of Geosciences, Beijing, China

Sepiolite was modified with $\mathrm{Al}^{3+}$ via hydrothermal reaction. The substitution amount of $\mathrm{Al}^{3+}$ for $\mathrm{Mg}^{2+}$ and $\mathrm{Si}^{4+}$ located at sepiolite lattice and the influence of substitution amount on the structure, specific surface area, and surface acidity of Al-modified sepiolite were investigated. On this basis, indigo-sepiolite composite pigments were prepared by Almodified sepiolite and indigo via grinding method to evaluate the influence of Al-modified sepiolite on the structure, bonding strength, and weather resistance of composite pigment. The crystal structure of Al-modified sepiolite had no obvious change after modification. $\mathrm{Al}^{3+}$ mainly substituted $\mathrm{Mg}^{2+}$ located at the octahedron of the sepiolite lattice, and the substitution amount was positively related to the dosage of $\mathrm{Al}^{3+}$. The specific surface area of Al-modified sepiolite decreased and the distribution of channel size became wider after Al modification. In addition, the absolute value of zeta potential decreased as well as the solid acid sites increased with the increase of Al substitution in Al-modified sepiolite. For indigo-sepiolite composite pigments, the structure of Almodified sepiolite had no obvious change as well. The adsorption amount of indigo in composite pigment after treating by DMSO and Al content as well as weak acid amount in Al-modified sepiolite presented linear correlation, indicating that Al modification could enhance the bonding strength between indigo and Al-modified sepiolite by increasing the amount of coordinated water with Al. For indigo, Al-modified sepiolite could brighten the color and reduce the weather resistance of the prepared composite pigment. The results of this study provide a new idea and basis for regulating the structure and properties of clay and for studying the preparation of composite pigment and clay functional materials.

Keywords: sepiolite, indigo, aluminum-modified, substitution, solid acidity

\section{INTRODUCTION}

Maya Blue (MB) pigment is an organic-inorganic composite pigment that widely exists in the murals and codes of ancient Maya ruins (Gettens, 1962; Giustetto et al., 2006; Arnold et al., 2012; Doménech-Carbó et al., 2014; Buti et al., 2018). It has attracted considerable attention because of its characteristic brightness after centuries of vicissitudes (José-Yacamán et al., 1996; Vandenabeele et al., 2005; Chiari et al., 2008; Grazia et al., 2020). MB was confirmed as a complex fabricated by precipitating indigo into palygorskite. Plenty of research studies on $\mathrm{MB}$ 
mainly concerned the type of attachment between indigo and palygorskite and the location of indigo in palygorskite to reveal the mystery of its unique stability (Giustetto et al., 2005; Chiari et al., 2008).

Sepiolite is widely used to prepare composite pigment with indigo and in turn compared with $\mathrm{MB}$ because it has a similar structure to palygorskite (Van Olphen, 1966; Giustetto et al., 2011). The result shows that the indigo-sepiolite composite pigment is less stable than MB (Sánchez Del Río et al., 2006; Giustetto et al., 2011). Both sepiolite and palygorskite are fibrous phyllosilicate formed by two continuous $\left[\mathrm{SiO}_{4}\right]$ tetrahedrons and an intermittent $\left[\mathrm{MgO}_{6}\right]$ octahedron, and the periodic inversion in $\left[\mathrm{SiO}_{4}\right]$ tetrahedron forms the channels of sepiolite and palygorskite. The difference between these two minerals is that the inverse period of $\left[\mathrm{SiO}_{4}\right]$ tetrahedron in sepiolite is 4 , while that in palygorskite is 6 , resulting in larger size of channels in sepiolite. In addition, the isomorphic substitution of $\mathrm{Al}^{3+}$ usually occurs in $\left[\mathrm{SiO}_{4}\right]$ tetrahedron and $\left[\mathrm{MgO}_{6}\right]$ octahedron in the two minerals, leading to different $\mathrm{Al}$ contents of palygorskite and sepiolite (Giulieri et al., 2012). Therefore, the difference in stability between the indigo-sepiolite composite pigment and $\mathrm{MB}$ is extremely possible due to the different channel sizes and $\mathrm{Al}$ content of the mineral substrate.

Silicate minerals possess acid-base conjugation formed by negative charge generated by isomorphic substitution, neutralized protons, and countercations in minerals (Ramírez et al., 2011; Tazi et al., 2012). The surface acidity is essentially determined by the electronegativity of the element bonding with oxygen (Busca, 1999), and thus, the Al content will directly affect the surface acidity and basicity of sepiolite and palygorskite. The acid and base in silicate minerals show catalytic activity in organic reactions, e.g., the pyrolysis behaviors of organic matters, the methylbutynol conversion, the Biginelli type reaction of aldehydes, and the synthesis of malononitrile prepolymers (Corma and Martín-Aranda, 1993; Hu et al., 2003; Niwa et al., 2010; Pushpaletha and Lalithambika, 2011; Liu et al., 2013a; Jha et al., 2013; Novikova et al., 2013; Bu et al., 2017; Phukan et al., 2017). The acid-base conjugation in minerals plays a role to fix organic molecules during the reaction, for example, in the polymerization reaction of $\mathrm{D}$, L-Lactid catalyzed by acidmodified montmorillonite, the $\mathrm{D}$, L-Lactid molecules were fixed on the accessible tetrahedral Al sites (act as acid sites) through oxygen atoms (Aslya et al., 2016). The amino group in aminobenzodifurandione dye was protonated by the acid bound to the oxygen atom of silanol (Lewis base) when probing the basicity of solid acids (Spange et al., 2005). In composite materials, the combination of organic molecules and inorganic substrates is usually affected by the solid surface acid. The flavylium dye was stabilized by the solid acid that is derived from an Al impurity in silicate (Kohno et al., 2008). The azobenzene molecule was protonated by Brönsted acid in $\mathrm{AlPO}_{4}-5$ zeolite and then interacted with the framework oxygen atoms (Polisi et al., 2018). The acidic site montmorillonite framework played an important role to form a strong bond with thioindigo (Ramírez et al., 2011). Indigo possesses a similar structure to thioindigo, and sepiolite and palygorskite have similar acid-base conjugation to silicate

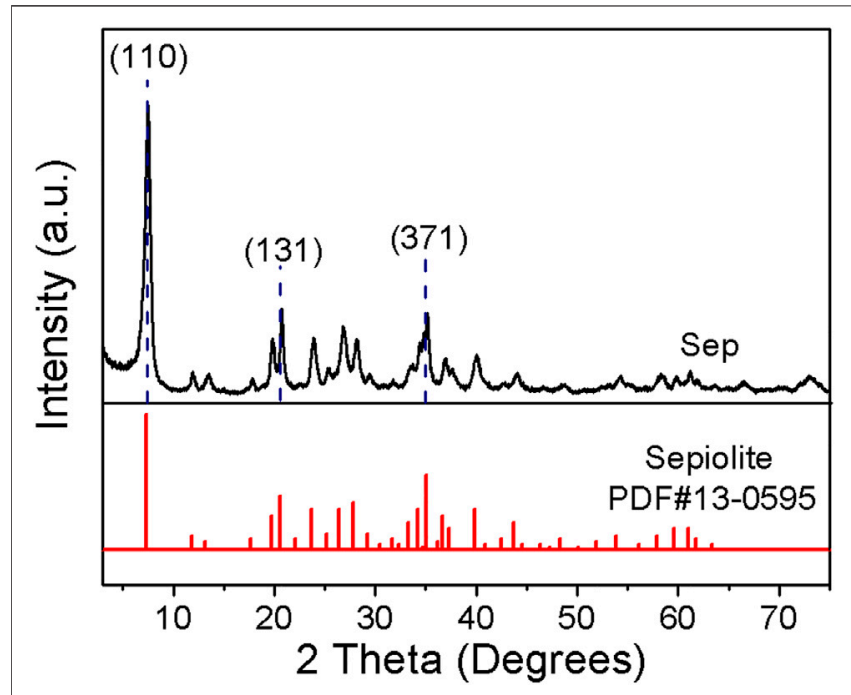

FIGURE 1 | XRD pattern of Sep.

minerals as well. Therefore, the acidity and basicity in sepiolite and palygorskite will also affect the bonding strength with indigo and the stability of the composite pigment, while it has not been discussed in the previous research.

The surface acidity and basicity of the minerals are affected by the modified cations since the electronegativity of cations changes. The basicity of sepiolite increased after being modified by $\mathrm{Fe}^{3+}$; therefore, Lewis acid $\mathrm{CH}_{3} \mathrm{Cl}$ had a greater affinity towards the modified sepiolite result from stronger acid-base interaction (Lazarevic et al., 2011). Two ways were used in cation modification to regulate the surface acidity and basicity of clay minerals. One is that the cations are simply adsorbed in the clay minerals. The polarization of these cations to adsorbed water molecules affects the acidity and basicity of the clay minerals. Montmorillonite, modified with $\mathrm{Zn}^{2+}, \mathrm{Fe}^{3+}$, and $\mathrm{Al}^{3+}$ through interlayer cation exchange, had increasing acidity in turn (Jha et al., 2013). Another is the substitution between free cations and lattice cations in clay minerals to change the acidity and basicity according to the electronegativity of cations. $\mathrm{Al}^{3+}, \mathrm{Cr}^{3+}, \mathrm{H}^{+}, \mathrm{Na}^{+}$, and $\mathrm{La}^{3+}$ were used to modify sepiolite, and only Al-modified sepiolite has super strength acid sites (Corma et al., 1991) since $\mathrm{Al}^{3+}$ was introduced in the octahedron of sepiolite, and then the catalytic activity of Almodified sepiolite for dehydration of ethanol and gasoil cracking was improved (Corma and Perez-Pariente, 1987; Zheng et al., 2010). Therefore, the $\mathrm{Al}$ content in the sepiolite can be regulated by the substitution of $\mathrm{Al}$ for the lattice cations in sepiolite, thereby changing the surface acidity of the sepiolite and the interaction between organic and inorganic substances.

In this study, sepiolite with low content of $\mathrm{Al}$ was modified by hydrothermal reaction with different dosages of $\mathrm{AlCl}_{3}$ to regulate its solid acidity. The obtained Al-modified sepiolite was used to prepare composite pigment with indigo via the grinding method. The bonding strength between indigo and Al-modified sepiolite and the weather resistance of the composite pigment were evaluated to explore the interaction between reactants. 
TABLE 1 | Chemical composition of Sep used in the study.

\begin{tabular}{lc}
\hline Component & Weight $\%$ \\
\hline $\mathrm{SiO}_{2}$ & 69.32 \\
$\mathrm{MgO}$ & 25.43 \\
$\mathrm{Al}_{2} \mathrm{O}_{3}$ & 2.89 \\
$\mathrm{~K}_{2} \mathrm{O}$ & 0.53 \\
$\mathrm{Fe}_{2} \mathrm{O}_{3}$ & 0.33 \\
$\mathrm{CaO}$ & 0.18 \\
$\mathrm{ZnO}$ & 0.14 \\
$\mathrm{TiO}_{2}$ & 0.10 \\
Others & 1.08
\end{tabular}

\section{EXPERIMENTAL}

\section{Materials}

Sepiolite (Sep) was obtained from Sigma-Aldrich (Shanghai) Trading Co., Ltd. The pattern of XRD and the chemical composition are given in Figure $\mathbf{1}$ and Table 1, respectively. $\mathrm{AlCl}_{3} \quad 6 \mathrm{H}_{2} \mathrm{O}$ (analytically pure) was purchased from Beijing Chemical Plant. Indigo (Id, purity of 98\%) was purchased from Shanghai Macklin Biochemical Technology Co., Ltd.

\section{Preparation of Al-Modified Sep}

The suspensions were prepared by mixing $7.00 \mathrm{~g}$ of Sep, $70 \mathrm{ml}$ of the solution containing different dosages of $\mathrm{AlCl}_{3} 6 \mathrm{H}_{2} \mathrm{O}(0.00$, $3.50,7.00$, and $70.0 \mathrm{mmol})$. The suspensions were kept in a $100 \mathrm{ml}$ tetrafluoroethylene-lined autoclave at $120^{\circ} \mathrm{C}$ for $10 \mathrm{~h}$. The precipitate was centrifuged and washed with deionized water until $\mathrm{Cl}^{-}$-ion-free and then dried at $60^{\circ} \mathrm{C}$ for $24 \mathrm{~h}$ in an oven. Finally, the dry precipitate was ground and passed through a 200 mesh sieve for further use. The resultant Al-modified Sep (AlSep) was marked as Al-x-Sep (x represents the amount of substance of $\mathrm{AlCl}_{3} 6 \mathrm{H}_{2} \mathrm{O}$, and the unit is mmol). In addition, the supernatant after centrifugation was collected and volumed to $2 \mathrm{~L}$, marked as "S".

\section{Preparation of Id-Al-Sep Composite Pigments}

Id was dispersed in deionized water, sonicated for $30 \mathrm{~min}$ in an ultrasonic cleaner (SN-4200 DTDN, Scientz, Zhejiang, China), and then shaken until the Id was evenly dispersed. $1 \mathrm{~g}$ of $\mathrm{Al}-\mathrm{x}$-Sep was mixed with $10 \mathrm{ml}$ of Id dispersion (Id/Sep is $0.125 \mathrm{mmol} / \mathrm{g}$ ) and milled in a planetary ball mill (XGB2, BYT, Jiangsu, China) at $560 \mathrm{rpm}$ for $2 \mathrm{~h}$. The obtained solid was dried, milled, and sieved (200-mesh sieve). The resultant composite pigment was labeled as Id-Al-x-Sep.

\section{Calculation of Substitution Amount of $\mathrm{Al}^{3+}$ for $\mathrm{Mg}^{2+}$ and $\mathrm{Si}^{4+}$ in Sep}

The consumption of $\mathrm{Al}^{3+}$ and the amount of $\mathrm{Mg}^{2+}$ and $\mathrm{Si}^{4+}$ substituted by $\mathrm{Al}^{3+}$ in Sep were tested and calculated by an inductively coupled plasma emission spectroscopy (ICP, ICAP7600, Thermo, United States). $3.5 \mathrm{ml}$ of $\mathrm{AlCl}_{3}$ solution for modification was diluted to $100 \mathrm{ml}$, marked as "Al". The supernatant " $\mathrm{S}$ " and diluted $\mathrm{AlCl}_{3}$ solution "Al" were then diluted by the same multiple $a$. The obtained solution was characterized by ICP to determine the concentration of $\mathrm{Al}^{3+}, \mathrm{Mg}^{2+}$, and $\mathrm{Si}^{4+}$. The substitution amount $R \quad(\mathrm{mmol} / \mathrm{g})$ (including the consumption of $\mathrm{Al}^{3+}$ and the amount of $\mathrm{Mg}^{2+}$ and $\mathrm{Si}^{4+}$ substituted by $\mathrm{Al}^{3+}$ in Sep) was calculated according to the following equation:

$$
R=\frac{2 \times\left|C_{I}^{S}-C_{I}^{A l}\right|}{M \times 7 a},
$$

where $C_{I}^{S}(\mathrm{ppm})$ and $C_{I}^{A l}(\mathrm{ppm})$ are the concentrations of ion $I$ in diluted solution " $\mathrm{S}$ " and " $\mathrm{Al}$," respectively, $M(\mathrm{~g} / \mathrm{mol})$ is the molar mass of ion $I, a$ is the dilution multiple of solution " $\mathrm{S}$ " and " $\mathrm{Al}$," 7 (g) refers to the mass of Sep during the $\mathrm{Al}$ modification, 2 stands for the volume of solution "S" $2 \mathrm{~L}$, and $I$ represents $\mathrm{Al}^{3+}, \mathrm{Mg}^{2+}$, and $\mathrm{Si}^{4+}$.

\section{Evaluation of Bonding Strength Between Id and Al-Sep}

$0.01 \mathrm{~g}$ of composite pigments was dispersed in $8 \mathrm{ml} \mathrm{DMSO}$ and shaken in a water bath shaker (SHA-B, Guohua, Jiangsu) at $30^{\circ} \mathrm{C}$ and $170 \mathrm{rpm}$ for $24 \mathrm{~h}$. The supernatants were separated by centrifugation and analyzed by a UV-Vis spectrophotometer (UV7600, Lengguang, Shanghai). The concentration of the supernatants was calculated by the Lambert-Beer law, and then, the adsorption amount of Id in Al-Sep was calculated to evaluate the bonding strength between Id and Al-Sep.

\section{Weather Resistance of Id-Al-Sep Composite Pigments}

$0.2 \mathrm{~g}$ of composite pigment was pressed into a glass groove with a diameter of $2 \mathrm{~cm}$, covered by a quartz glass, and irradiated by a UV lamp (AC/90-240 V, Zigu, Guangzhou) with a wavelength of $395 \mathrm{~nm}$ and radiation intensity of $650 \mathrm{~mW} / \mathrm{cm}^{2}$. The CIE of composite pigment irradiated by a UV lamp at different times was measured by a colorimeter (NR60CP, $3 \mathrm{nh}$, Guangzhou). The following formula was used to calculate the color difference $(\Delta E)$ :

$$
\Delta E=\sqrt{\left(L_{1}-L_{0}\right)^{2}+\left(a_{1}-a_{0}\right)^{2}+\left(b_{1}-b_{0}\right)^{2}},
$$

where $(L, a, b)$ reflects the lightness, red-green, and yellow-blue of the pigment, respectively, determining the color of the pigment. $\left(L_{1}, a_{1}, b_{1}\right)$ and $\left(L_{0}, a_{0}, b_{0}\right)$ are the average of three measurements collected on the pigments after and before UV irradiation, respectively. $\Delta E$ reflects the weather resistance of the composite pigments; the smaller $\Delta E$, the better the weather resistance (Ouellet-Plamondon et al., 2015).

\section{Characterization}

The chemical composition of Al-Sep was analyzed by an X-ray fluorescence spectrometer (XRF, XRF-1800, Shimadzu, Japan). $0.1 \mathrm{~g}$ of Al-Sep powder was pressed with boric acid into a tablet for analysis. The morphology of samples was characterized by a transmission electron microscopy (TEM, JEM-2100Plus, JEOL). 
TABLE 2 | The substitution amount $(\mathrm{mmol} / \mathrm{g})$ of $\mathrm{Al}^{3+}, \mathrm{Mg}^{2+}$, and $\mathrm{Si}^{4+}$.

\begin{tabular}{lccc}
\hline Samples & Al & Mg (-) & Si (-) \\
\hline Al-0.00-Sep & 0.0000 & 0.0056 & 0.0197 \\
Al-3.50-Sep & 0.4785 & 0.6855 & 0.1061 \\
Al-7.00-Sep & 0.8621 & 1.2498 & 0.1709 \\
Al-70.0-Sep & 1.5831 & 1.6756 & 0.1017 \\
\hline
\end{tabular}

(-) indicates that the ion was substituted by $A \beta^{3+}$.

The Fourier Transform infrared (FTIR) spectra were carried out by a FTIR spectrometer (Spectrum 100, PerkinElmer, United States) range from 1,200 to $2000 \mathrm{~cm}^{-1}$ with $\mathrm{KBr}$ background. X-ray diffraction (XRD) pattern used X-ray diffractometer (B8 Advance, Bruker, Germany) operating at $\mathrm{Cu} \mathrm{Ka}, 40 \mathrm{~mA}$, and $20 \mathrm{kV}$, scanning from $3^{\circ}$ to $80^{\circ}$ with a rate of $8^{\circ} / \mathrm{min}$. The zeta potential $(\zeta)$ was tested by a zeta potential analyzer (Zetasizer Nano ZS90, Malvern, United Kingdom), and $0.01 \mathrm{~g}$ of sample was dispersed in $10 \mathrm{ml}$ deionized water with sonication for $30 \mathrm{~min}$. The specific surface area (BET method) of the sample was obtained from the adsorption-desorption isotherm of $\mathrm{N}_{2}$ measuring by a specific surface area and pore size analyzer (Autosorb IQ, Quantachrome, United States of America) at $77 \mathrm{~K}$. The sample was firstly degassed at $120^{\circ} \mathrm{C}$ for $2 \mathrm{~h}$. The pore size distribution of the sample was calculated by the density functional theory (DFT) model. The ${ }^{27} \mathrm{Al} \mathrm{NMR}$ one-pulse signal was obtained by a nuclear magnetic resonance instrument (Bruker AVANCE III $600 \mathrm{M}$, Bruker, Germany) at the frequency of $156.38 \mathrm{MHz}$ and the tube diameter of $3.2 \mathrm{~mm}$. The chemical shift of ${ }^{27} \mathrm{Al}$ resonance line was referred to $\mathrm{Al}\left(\mathrm{NO}_{3}\right)_{3}$ aqueous solution. The ${ }^{27} \mathrm{Al}$ experiment was recorded with a spinning rate of $15 \mathrm{kHz}$, relaxation delay of $1 \mathrm{~s}$, and number of scans of 1,024 . The TPD analysis was carried out by a chemical adsorption analyzer (AutoChem II 2,920, Micromeritics, United States). $0.1 \mathrm{~g}$ of sample was pretreated with $\mathrm{Ar}$ gas at $160^{\circ} \mathrm{C}$, and $\mathrm{NH}_{3}$ was then introduced until the adsorption of the sample was saturated. Following $\mathrm{NH}_{3}$ adsorption, $\mathrm{Ar}$ gas was used to remove residual $\mathrm{NH}_{3}$ on the surface of the sample. Finally, the sample was degassed at a rate of $10^{\circ} \mathrm{C} / \mathrm{min}$ from 50 to $600^{\circ} \mathrm{C}$, and the desorbed $\mathrm{NH}_{3}$ at different temperatures was collected.

\section{RESULTS AND DISCUSSION}

\section{Preparation of Al-Modified Sep The Influence of Al Dosage on the Composition of Al-Modified Sep}

The consumption of $\mathrm{Al}^{3+}$ and the substitution amount of $\mathrm{Mg}^{2+}$ and $\mathrm{Si}^{4+}$ in Sep were calculated by Eq. (1), shown in Table 2. For Al-0.00-Sep, traces of $\mathrm{Mg}^{2+}$ and $\mathrm{Si}^{4+}$ exist in the solution "S," indicating that traces of $\mathrm{Mg}^{2+}$ and $\mathrm{Si}^{4+}$ elute from the Sep during the hydrothermal reaction even without $\mathrm{AlCl}_{3}$. After introducing $\mathrm{AlCl}_{3}$, the substitution amount of $\mathrm{Mg}^{2+}$ and $\mathrm{Si}^{4+}$ (i.e., the amounts of $\mathrm{Mg}$ and $\mathrm{Si}$ dissolved from Sep) increases, demonstrating that $\mathrm{Al}^{3+}$ can promote the substitution of $\mathrm{Mg}^{2+}$ and $\mathrm{Si}^{4+}$ in Sep. The consumption of $\mathrm{Al}^{3+}$ and the substitution amount of $\mathrm{Mg}^{2+}$ increase, while the substitution amount of $\mathrm{Si}$

has no obvious change with the increase in dosage of $\mathrm{AlCl}_{3}$. As the dosage of $\mathrm{AlCl}_{3}$ reaches $70.0 \mathrm{mmol}$, the substitution amounts of $\mathrm{Al}^{3+}, \mathrm{Mg}^{2+}$, and $\mathrm{Si}^{4+}$ are $1.5831 \mathrm{mmol} / \mathrm{g}, 1.6756 \mathrm{mmol} / \mathrm{g}$, and $0.1017 \mathrm{mmol} / \mathrm{g}$, revealing that the substitution of $\mathrm{Al}^{3+}$ mainly occurs with $\mathrm{Mg}^{2+}$.

Table 3 shows the element content of Al-Sep modified by different dosages of $\mathrm{AlCl}_{3}$ characterized by XRF. As the dosage of $\mathrm{AlCl}_{3}$ increases, the content of $\mathrm{Al}$ in Sep increases, the content of $\mathrm{Mg}$ gradually decreases, while the content of Si has no significant change, which is consistent with the substitution amount result exhibited in Table 2. The content of $\mathrm{Cl}$ in Al-Sep is less than $0.10 \%$, which is significantly lower than the content of $\mathrm{Al}$ in the samples, indicating that $\mathrm{Cl}^{-}$adsorbed on the surface of Al-Sep during the modification process is effectively removed.

According to the calculation of the ion substitution amount and characterization of XRF, the composition of Al-Sep is mainly changed via the substitution of $\mathrm{Al}^{3+}$ for $\mathrm{Mg}^{2+}$ in Sep during the $\mathrm{Al}$ modification process. Since the radius of $\mathrm{Al}^{3+}$ is smaller than that of $\mathrm{Mg}^{2+}$ and the charge of $\mathrm{Al}^{3+}$ is larger than that of $\mathrm{Mg}^{2+}$, the substitution of $\mathrm{Al}^{3+}$ for $\mathrm{Mg}^{2+}$ can reduce the energy and stabilize the system (Liao and Xia, 2013).

\section{The Structure of Al-Modified Sep}

Figure 2 presents the XRD patterns of Sep and Al-Sep. The typical reflection peaks of Sep are located at $2 \theta=7.45^{\circ}, 20.53^{\circ}$, and $34.92^{\circ}$ corresponding to (110), (131), and (371) planes, according to JCPDS card no. 13-0595 (Figure 1), without other impurity peaks. The peaks of Al-Sep are identical with that of Sep (Figure 2A), suggesting that the fiber structure of sepiolite has no significant change, and no impurity crystal is formed during the modification. The reflection peaks at a small angle of Al-Sep shift to a low angle slightly compared with that of Sep, and as the dosage of $\mathrm{AlCl}_{3}$ increases, the shift angle increases (Figure 2B). The diffraction angles at (110) plane in Sep, Al-3.50-Sep, and Al70.0 -Sep are $7.45^{\circ}, 7.43^{\circ}$, and $7.34^{\circ}$, respectively, corresponding to the interplanar spacing of $11.85 \AA, 11.89 \AA$, and $12.03 \AA$, revealing that the interplanar space of (110) plane increases as the dosage of $\mathrm{Al}$ increases. The change in the interplanar space and the difference between the radii of $\mathrm{Al}^{3+}$ and $\mathrm{Mg}^{2+}$ are in the same order of magnitude; therefore, the shift of diffraction angle at (110) plane is attributed to a slight distortion of the sepiolite during the modification process.

\section{The Morphology of Al-Modified Sep}

Figure 3 provides the TEM images of Sep, Al-3.50-Sep, and Al70.0 -Sep. The length of Sep is about $0.5-6 \mu \mathrm{m}$, the width is about $20 \mathrm{~nm}$, and Sep mainly exists as single nanofibers (Figure 3A, D).

TABLE 3 | Element content of Al-Sep modified by $\mathrm{AlCl}_{3}$ with different dosages.

Sample

$\mathbf{S i}$
32.58
32.18
32.30
32.88

\section{Element content (\%)}

$\begin{array}{ccccccc}\mathbf{M g} & \text { Al } & \mathbf{F} & \mathbf{K} & \mathbf{F e} & \mathbf{C a} & \mathbf{C l} \\ 15.42 & 1.36 & 0.77 & 0.47 & 0.26 & 0.12 & 0.01 \\ 13.92 & 3.12 & 0.73 & 0.56 & 0.27 & 0.03 & 0.01 \\ 12.37 & 4.51 & 0.67 & 0.43 & 0.25 & 0.02 & 0.01 \\ 10.64 & 5.43 & 0.51 & 0.41 & 0.24 & 0.01 & 0.10\end{array}$



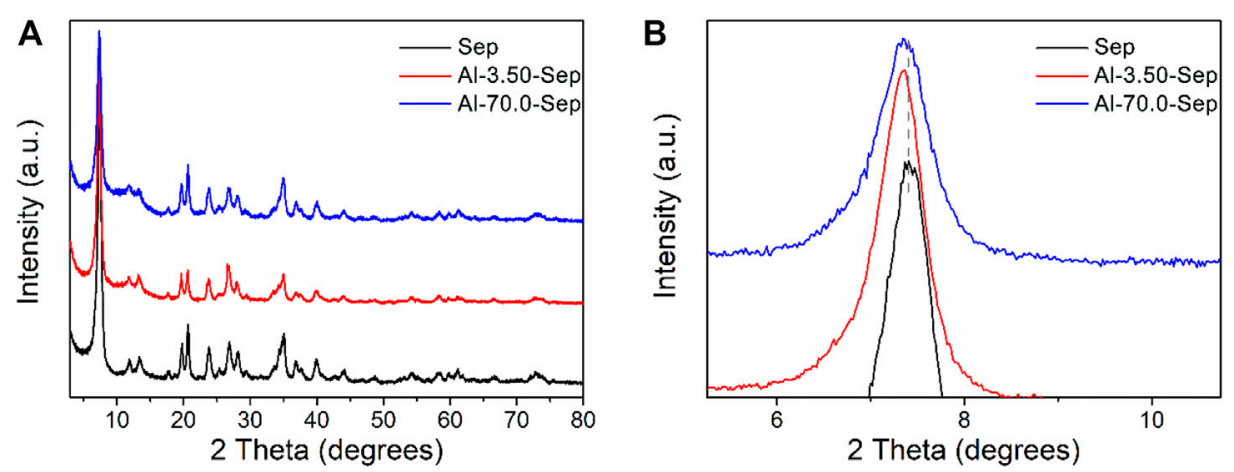

FIGURE 2 | (A) XRD patterns of Sep, Al-3.50-Sep, and Al-70.0-Sep. (B) Partially enlarged view of Figure 2 A.
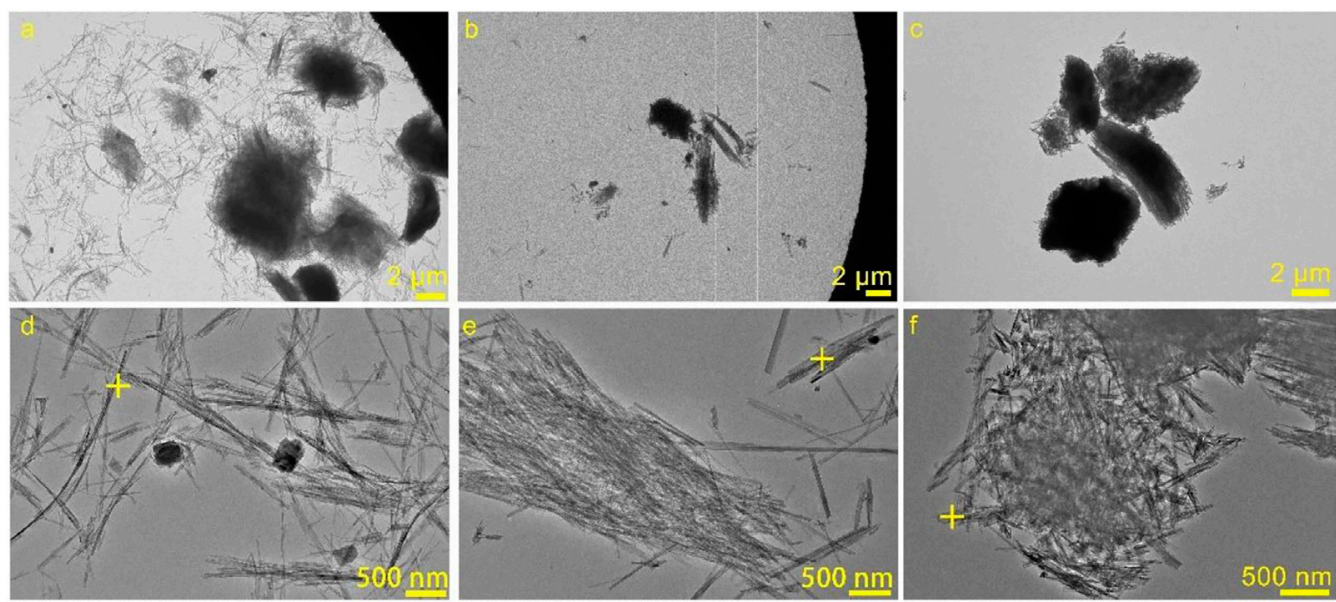

FIGURE 3 | TEM images of (A, D) Sep, (B, E) Al-3.50-Sep, and (C, F) Al-70.0-Sep

TABLE 4 | The corresponding EDS results marked in Figures 3D-F.

\begin{tabular}{lccccc} 
Samples & Al & Mg & Si & $\mathbf{~}$ & $\mathbf{C l}$ \\
\hline Sep & 0 & 10.30 & 27.09 & 44.41 & 0 \\
Al-3.50-Sep & 1.78 & 9.70 & 33.37 & 55.10 & 0.05 \\
Al-70.0-Sep & 3.12 & 6.97 & 33.72 & 56.18 & 0.00 \\
\hline
\end{tabular}

As illustrated in Figure 3B, C, the fibrous structure of sepiolite has not been destroyed after being modified by $\mathrm{AlCl}_{3}$ while the single fibers obviously decrease, indicating that $\mathrm{Al}$ modification will reduce the dispersibility of sepiolite. From the results of EDSpoint (Table 4) on the sepiolite fibers marked in Figure 3D-F, the main elements on the fiber in Sep are $\mathrm{O}, \mathrm{Si}$, and $\mathrm{Mg}$, and the elements $\mathrm{Al}$ and $\mathrm{Cl}$ appear on the fiber of Al-3.50-Sep after introducing $\mathrm{AlCl}_{3}$. The content of $\mathrm{Al}$ in $\mathrm{Al}-70.0-\mathrm{Sep}$ is significantly increased, demonstrating that the element $\mathrm{Al}$ exists on the fibers of sepiolite during the hydrothermal reaction with $\mathrm{AlCl}_{3}$, and the content increases with the increase of the dosage of $\mathrm{AlCl}_{3}$.

\section{The Substitution Position of $\mathrm{Al}^{3+}$}

The substitution position of $\mathrm{Al}^{3+}$ was distinguished by solid-state

${ }^{27} \mathrm{Al}$ NMR spectra, shown in Figure 4. The signals are observed at $\sim 7$ and $\sim 70 \mathrm{ppm}$, attributed to octahedral $\left[\mathrm{AlO}_{6}\right]\left(\mathrm{Al}_{\mathrm{T}}\right)$ and tetrahedral $\left[\mathrm{AlO}_{4}\right]\left(\mathrm{Al}_{\mathrm{O}}\right)$ in the structure of sepiolite, respectively (Caillerie and Fripiat, 1992; Komarneni et al., 1986). The $\mathrm{Al}_{\mathrm{T}}$ and $\mathrm{Al}_{\mathrm{O}}$ in Sep occur due to amorphous impurity and the substitution of $\mathrm{Al}^{3+}$ for $\mathrm{Mg}^{2+}$ located at $\left[\mathrm{MgO}_{6}\right]$ and $\mathrm{Si}^{4+}$ located at $\left[\mathrm{SiO}_{4}\right]$ in sepiolite lattice. The intensity of ${ }^{27} \mathrm{Al}$ NMR signal reflects the content of $\mathrm{Al}$, and the peak area of the signal can be integrated to calculate the content of $\mathrm{Al}$ at different positions, shown in Figure 4C, D. The width of the signal reflects the symmetry of Al complex, and the narrower spectrum reflexes the higher symmetry of the complex (Wang et al., 2000).

For Sep, two bands of $\mathrm{Al}_{\mathrm{O}}$ at $7.5 \pm 0.5 \mathrm{ppm}$ and $-2 \pm 1 \mathrm{ppm}$, deriving from the $\mathrm{Al}$ at the edge $\left(\mathrm{Al}_{\mathrm{O}} 2\right)$ and the section $\left(\mathrm{Al}_{\mathrm{O}} 1\right)$ of the octahedron in sepiolite, and two signals of $\mathrm{Al}_{\mathrm{T}}$ at $65 \pm 1 \mathrm{ppm}$ and $74 \pm 1 \mathrm{ppm}$, corresponding to the $\mathrm{Al}$ at the center $\left(\mathrm{Al}_{\mathrm{T}} 2\right)$ and edge $\left(\mathrm{Al}_{\mathrm{T}} \mathrm{l}\right)$ of tetrahedron in sepiolite, are very close to the 

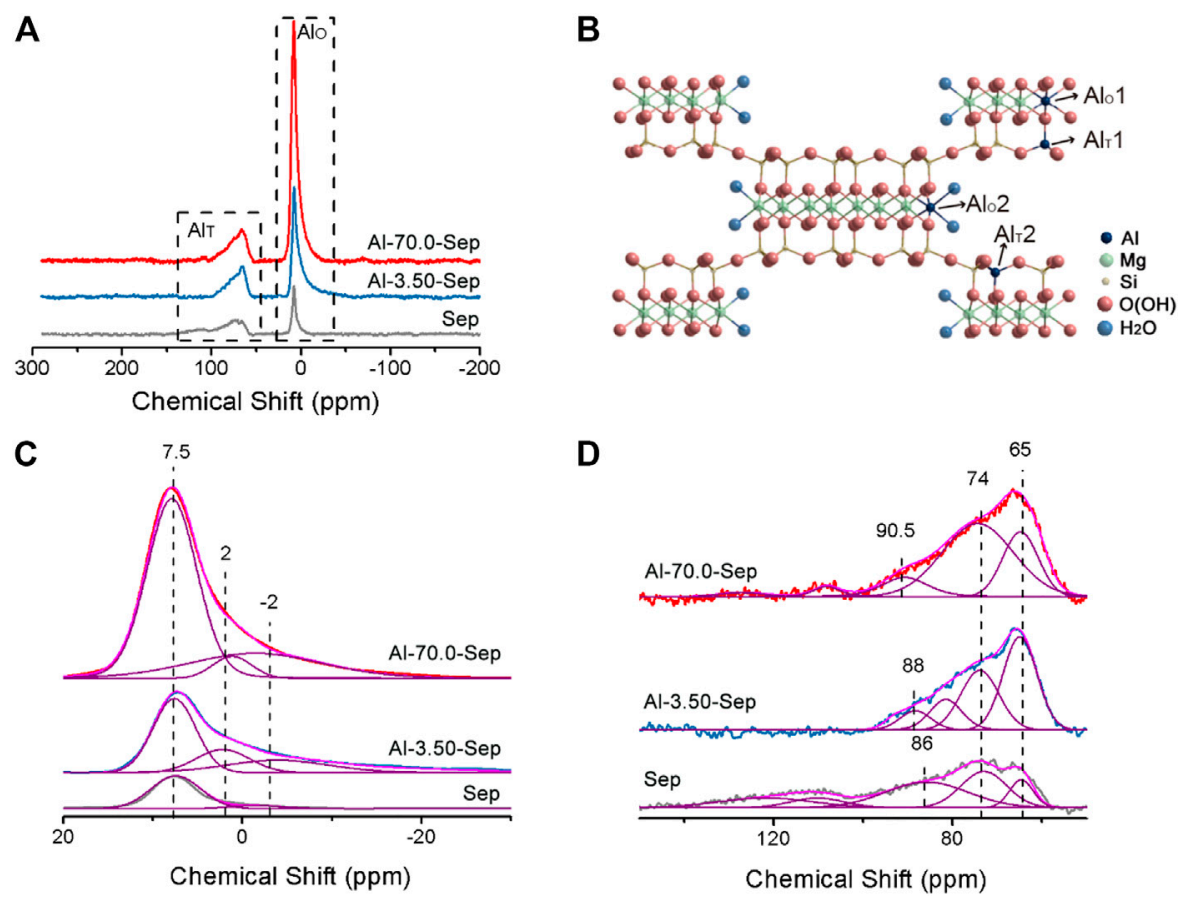

D

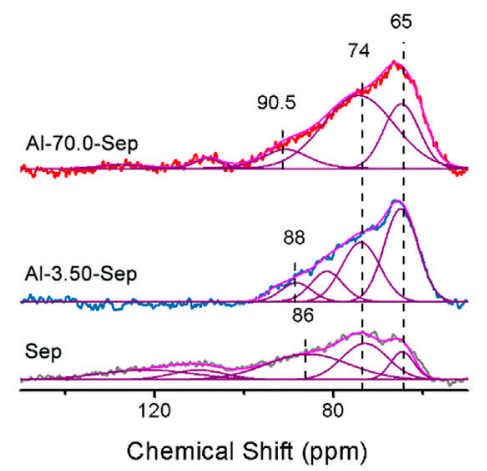

FIGURE 4 | (A) ${ }^{27}$ Al NMR spectra of Sep, Al-3.50-Sep, and Al-70.0-Sep. (B) Schematic diagram of the position of $\mathrm{Al}_{\mathrm{T}}$ and $\mathrm{Al}$, in sepiolite. The simulated results of (A) (C) at 20 -30 ppm and (D) at 150 50 ppm.

TABLE 5 | The calculated results of ${ }^{27}$ Al NMR spectra of Sep, Al-3.50-Sep, and Al-70.0-Sep.

\begin{tabular}{|c|c|c|c|c|c|c|c|c|c|}
\hline \multirow[t]{2}{*}{ Samples } & \multirow[t]{2}{*}{ Al (wt.\%) } & \multirow[t]{2}{*}{$A \mathbf{l}_{\mathrm{T}}$ (wt.\%) } & \multicolumn{3}{|c|}{$\mathbf{A l}_{\mathrm{T}}(\mathrm{ppm})$} & \multirow[t]{2}{*}{$\mathrm{Al}_{\mathrm{O}}$ (wt.\%) } & \multicolumn{3}{|c|}{$\mathrm{Al}_{\mathrm{O}}(\mathrm{ppm})$} \\
\hline & & & 65 & 74 & 86 & & -2 & 2 & 7.5 \\
\hline Sep & 1.53 & 0.69 & 0.10 & 0.26 & 0.33 & 0.57 & 0.05 & 0 & 0.52 \\
\hline Al-70.0-Sep & 5.43 & 1.40 & 0.48 & 0.76 & 0.15 & 3.91 & 1.03 & 0.20 & 2.69 \\
\hline
\end{tabular}

previous literature, marked in Figure 4B (Caillerie and Fripiat, 1992; Wang et al., 2000; Aslya et al., 2016). The signals at $86 \pm$ $5 \mathrm{ppm}$ are broad, revealing poor symmetry, which might be from the $\mathrm{Al}$ in the tetrahedron in the amorphous impurity (Wang et al., 2000). The ${ }^{27} \mathrm{Al}$ signals in Sep come from the impurity and the substitution of $\mathrm{Mg}^{2+}$ in the octahedron and $\mathrm{Si}^{4+}$ in tetrahedron by $\mathrm{Al}^{3+}$ during the mineralization process (Zhuang et al., 2019).

The intensity of ${ }^{27} \mathrm{Al}$ signals of Al-3.50-Sep and Al-70.0-Sep is higher than that of Sep, illustrating the content of $\mathrm{Al}$ increases after modification, which is consistent with the result of ICP and XRF. Al-3.50-Sep and Al-70.0-Sep have similar chemical shifts to Sep, revealing that $\mathrm{Al}^{3+}$ can enter the tetrahedron and octahedron in sepiolite, rather than just forming oxides or adsorbing on the surface of sepiolite. Al-Sep has a signal at $2 \pm 1 \mathrm{ppm}$ that is absent in Sep, which belongs to the chemical shift for amorphous aluminum silicate formed during the hydrothermal reaction. The signal of Al-0.05-Sep at $86 \pm 5 \mathrm{ppm}$ is divided into two signals, which are attributed to the change of the impurity in sepiolite and then the formation of two kinds of $\mathrm{Al}_{\mathrm{T}}$ with different chemical environments.
The content of $\mathrm{Al}$ at different positions in sepiolite of samples is calculated and shown in Table 5. The Al content at $-2 \pm 1 \mathrm{ppm}$ and $7.5 \pm 0.5 \mathrm{ppm}$ increased significantly as the dosage of $\mathrm{AlCl}_{3}$ increases, indicating that $\mathrm{Al}^{3+}$ mainly substitutes the $\mathrm{Mg}^{2+}$ at the edge and section of the octahedron in sepiolite. $\mathrm{Al}^{3+}$ can substitute $\mathrm{Si}^{4+}$ in tetrahedron as well, but the substitution amount is obviously lower than that occurs in the octahedron. In addition, the signals at 108 and $127 \mathrm{ppm}$ are the chemical shift produced by the tetrahedral coordination formed by $\mathrm{Al}^{3+}, \mathrm{Cl}^{-}$, and $\mathrm{F}^{-}$adsorbed on the surface of sepiolite (Wang et al., 2000).

\section{The Specific Surface Area and Micropores of Al-Modified Sep}

The $\mathrm{N}_{2}$ adsorption-desorption isotherms and the pore size distribution plots of Sep, Al-3.50-Sep, and Al-70.0-Sep are shown in Figure 5. As illustrated in Figure 6A, the $\mathrm{N}_{2}$ amounts adsorbed on Al-3.50-Sep and Al-70.0-Sep are smaller than that adsorbed on Sep, indicating they have a smaller specific surface area, as the dispersibility of sepiolite rapidly reduces after Al modification (exhibited in Figure 3). The micropores ranging 

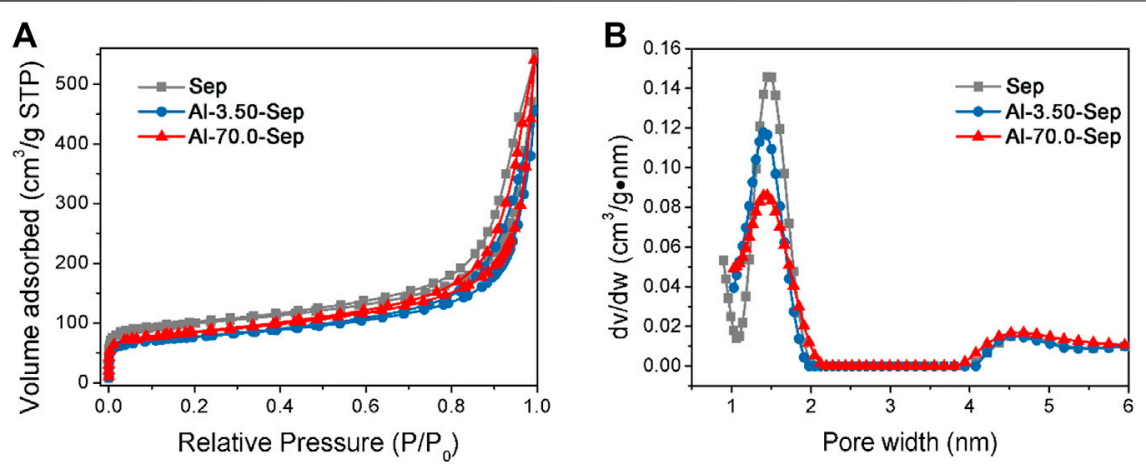

FIGURE 5 | (A) $\mathrm{N}_{2}$ adsorption-desorption isotherms and (B) the pore size distribution plots of Sep, Al-3.50-Sep, and Al-70.0-Sep.
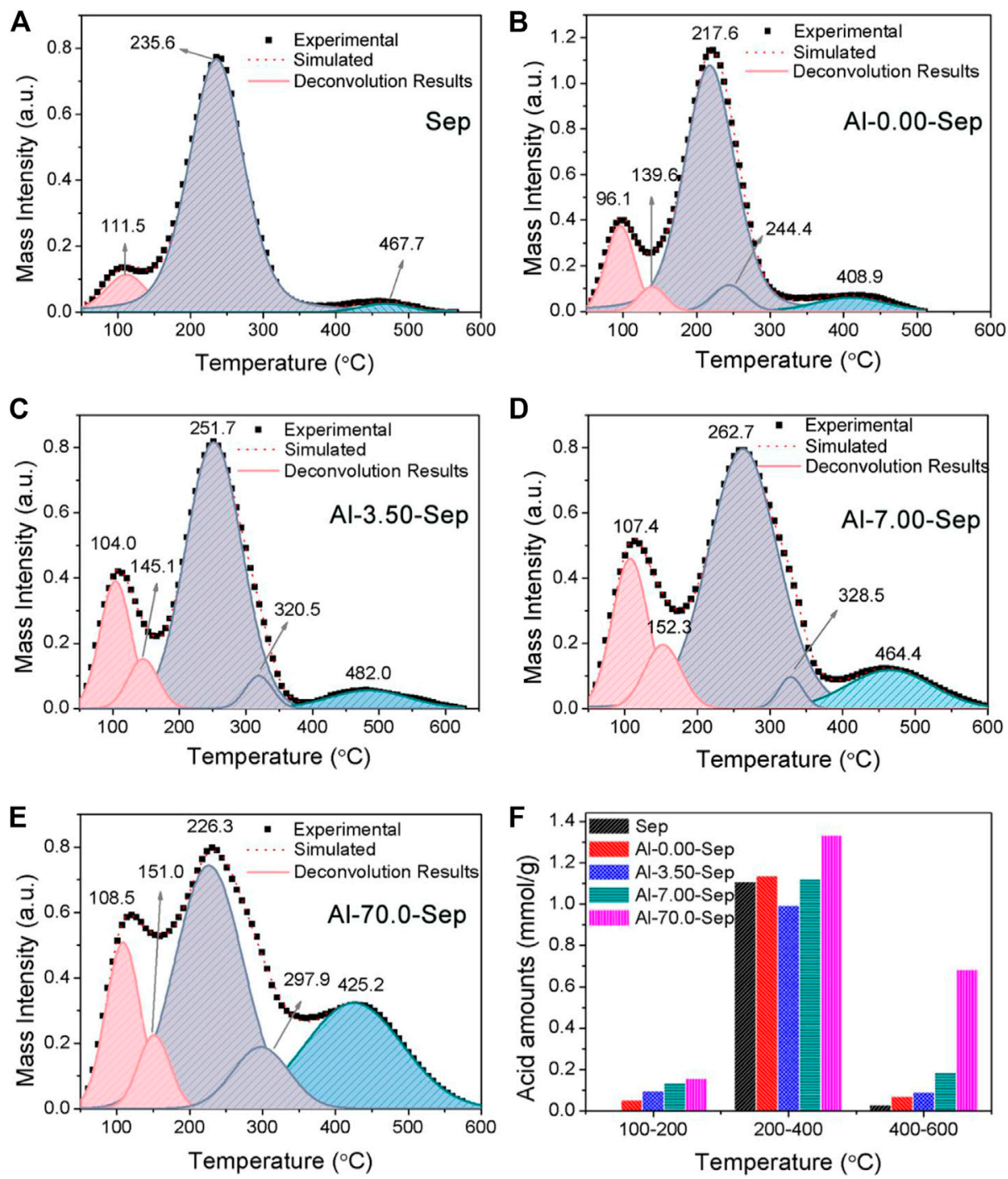

FIGURE 6 | The $\mathrm{NH}_{3}$-TPD curves after heating from 50 to $600^{\circ} \mathrm{C}$ of (A) Sep, (B) Al-0.00-Sep, (C) Al-3.50-Sep, (D) Al-7.00-Sep, and (E) Al-70.0-Sep. (F) The acid amounts of samples. 
TABLE 6 | The zeta potential of Al-Sep modified with different dosages of $\mathrm{AlCl}_{3}$.

\begin{tabular}{lcccc} 
Samples & Al-0.00-sep & Al-3.50-sep & Al-7.00-sep & Al-70.0-sep \\
\hline$\zeta(\mathrm{mV})$ & -13.5 & -10.8 & -9.25 & -6.17
\end{tabular}

from 1 to $2 \mathrm{~nm}$ represent the channels of sepiolite formed by the periodic reversal of $\left[\mathrm{SiO}_{4}\right]$ (Chen et al., 2019). As the dosage of $\mathrm{AlCl}_{3}$ increases, the distribution of channel size becomes wide, since the substitution of $\mathrm{Al}^{3+}$ for $\mathrm{Mg}^{2+}$ at the edge and section of the octahedron, i.e., the edge of sepiolite channel, makes the distribution of sepiolite channel size becoming uneven.

\section{The Zeta Potential of Al-Modified Sep}

Table 6 gives the zeta potential of Al-Sep. The following possibilities will occur during the Al modification: 1) the substitution of $\mathrm{Al}^{3+}$ for $\mathrm{Mg}^{2+}$ in the octahedron will reduce the negative surface charges; 2) the substitution of $\mathrm{Al}^{3+}$ for $\mathrm{Si}^{4+}$ in tetrahedron will increase the negative surface charges; 3) the formation of vacancy defects in the octahedron and tetrahedron will increase the negative surface charges; and 4) the adsorption of $\mathrm{Al}^{3+}$ on sepiolite surface will reduce the negative charges. These actions conduct at the same time and affect the final zeta potential of the sepiolite. The result shows that the absolute value of the zeta potential decreases with the increase of dosage of $\mathrm{AlCl}_{3}$, since the substitution of $\mathrm{Al}^{3+}$ mainly occurs on the octahedron in sepiolite and reduces the negative charge on the sepiolite surface.

\section{The Solid Acidity of Al-Modified Sep}

$\mathrm{NH}_{3}$-TPD has been verified to characterize the solid acidity of clay mineral quantitatively by calculating relative areas of resolved bands. The acid strength is positively correlated with the desorption temperature of $\mathrm{NH}_{3}$ (Liu et al., 2013b). The acidity of montmorillonite is formed by the water polarized by cations, Si-OH and $\mathrm{H}_{3} \mathrm{O}^{+}$adsorbed on the negative charges, unsaturated $\mathrm{Al}^{3+}$ in the octahedron, and adsorbed water on unsaturated $\mathrm{Al}^{3+}$ (marked as Al- $\mathrm{OH}_{2}$ ) (Heller-Kallai, 2006; Liu et al., 2013b; Liu et al., 2011). $\mathrm{Si}-\mathrm{OH}, \mathrm{H}_{3} \mathrm{O}^{+}$, and $\mathrm{Al}-\mathrm{OH}_{2}$ behave as weak-strength acid sites (Hair and Hertl, 1970). The polarized water and unsaturated $\mathrm{Al}^{3+}$ behave as medium-strength acid site. The water polarized by adsorbed cations, e.g., $\mathrm{Al}^{3+}, \mathrm{Ca}^{2+}$, and $\mathrm{Fe}^{3+}$, will be transformed into exposed hydroxy and then behaves as strong-strength acid site after heating at $160^{\circ} \mathrm{C}$ (Liu et al., 2013b; Kaufhold et al., 2011). The acid sites of sepiolite are similar to montmorillonite; therefore, the bands of $\mathrm{NH}_{3}$-TPD curves of samples (shown in Figure 6A-E) at $100-200^{\circ} \mathrm{C}, 200-400^{\circ} \mathrm{C}$, and $400-600^{\circ} \mathrm{C}$ correspond to weak-strength, medium-strength, and strong-strength acid sites, respectively. In addition, the desorption temperature occurs at $\sim 100^{\circ} \mathrm{C}$ attributed to physical adsorbed and hydrogen-bound $\mathrm{NH}_{3}$ (Liu et al., 2011; Liu et al., 2013b). The total acid amounts of Sep, Al-0.00-Sep, Al-3.50-Sep, Al-7.00-Sep, and Al-70.0-Sep are 1.137, 1.273, 1.177, 1.440, and $2.220 \mathrm{mmol} / \mathrm{g}$. The amounts of weak-strength and strongstrength acid sites increase while the amount of mediumstrength acid sites firstly decreases and then increases with the increase of the dosage of $\mathrm{AlCl}_{3}$ (Figure 6F).
Compared with Sep, the acid amount in Al-0.00-Sep increases, since $\mathrm{Mg}^{2+}$ and $\mathrm{Si}^{4+}$ in sepiolite lattice are dissolved out during the hydrothermal reaction, resulting in the increase of negative charge and the adsorbed $\mathrm{H}_{3} \mathrm{O}^{+}$. The grinding process during the preparation of Al-0.00-Sep can also increase acid sites by increasing the unsaturated cations and then enhancing the polarization of adsorbed water.

The weak-strength and strong-strength acid sites increase while the medium-strength acid sites reduce in Al-3.50-Sep, since the $\mathrm{Al}-\mathrm{OH}_{2}$ at the edge of the octahedron and exposed octahedral $\mathrm{Al}-\mathrm{OH}$ increase and the unsaturated $\mathrm{Al}^{3+}$ decreases (Figure 4C) after being modified by $3.50 \mathrm{mmol} \mathrm{AlCl}_{3}$. With the increase in dosage, the $\mathrm{Al}-\mathrm{OH}_{2}$, unsaturated $\mathrm{Al}^{3+}$, and exposed $\mathrm{Al}-\mathrm{OH}$ increase, and thus, the weak-, medium-, and strongstrength acid amounts are improved. TPD results illustrate that Al modification will increase the acid sites of sepiolite.

\section{The Id-Al-Sep Composite Pigments The Structure of Id-Al-Sep Composite Pigments $X$-Ray Diffraction}

Id was employed as the color giving agent and ground with sepiolite modified with different dosages of $\mathrm{AlCl}_{3}$ to prepare composite pigments. The structure of composite pigments was characterized by XRD, shown in Figure 7A. The typical reflection peaks of Id-Al-3.50-Sep are identical with that of Sep, and no obvious reflection belonging to Id is observed in Id-Al-3.50-Sep, revealing that the Id molecule is uniformly distributed on Al-Sep after grinding.

\section{Fourier Transform Infrared}

Figure 7B shows the FTIR spectra of Id, Sep, and composite pigments, and the stretching vibration of $\mathrm{C}=\mathrm{O}$ and $\mathrm{N}-\mathrm{H}$ at $1,626 \mathrm{~cm}^{-1}$ redshifts to $1,624 \mathrm{~cm}^{-1}$, corresponding to the shift caused by the formation of hydrogen bond between indigo and two water molecules which were calculated by the literature (Giustetto et al., 2005), demonstrating that $\mathrm{C}=\mathrm{O}$ and $\mathrm{N}-\mathrm{H}$ in Id can bond with the coordinated water, silanol, and zeolite water in Al-Sep through hydrogen bond. The vanishment of the vibration of $1,391 \mathrm{~cm}^{-1}$ attributed to crystalline indigo indicates the absence of crystalline indigo in composite pigments (Giulieri et al., 2012).

As illustrated by the results of XRD and FTIR, the presence of crystalline indigo is not detected in the composite pigment, indicating Id molecules reorganize on the Al-Sep during ball milling. Id molecules bond through hydrogen bond with coordinated water, silanol, and zeolite water in Al-Sep.

\section{The Bonding Strength Between Id and Al-Sep}

The composite pigments were desorbed by DMSO to evaluate the effect of Al modification on bonding strength between Id and AlSep. The removal of Id by DMSO can be an indication of available Id in Al-Sep with different bonding strengths, and the UV-Vis spectra of supernatant after desorption are shown in Figure 8A. As the dosage of modified $\mathrm{AlCl}_{3}$ increases, the $\mathrm{Al}$ content in sepiolite increases, and the desorption number of composite pigments in DMSO decreases, indicating that the bonding strength between Id and Al-Sep increases. Compared with the 

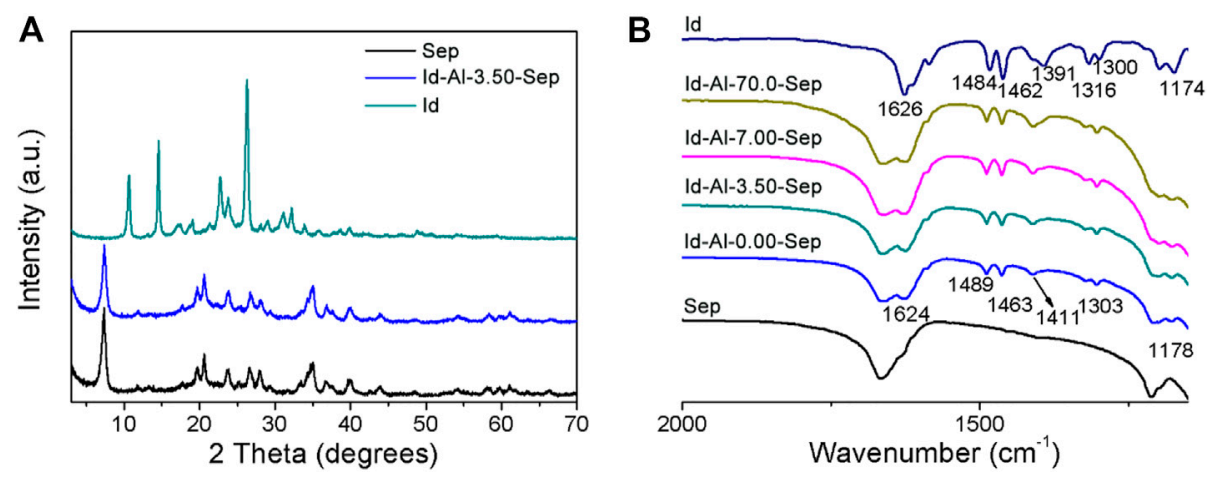

FIGURE 7 | (A) XRD pattern and (B) FTIR spectra of Sep, Id, and composite pigment prepared by Id and Al-Sep.
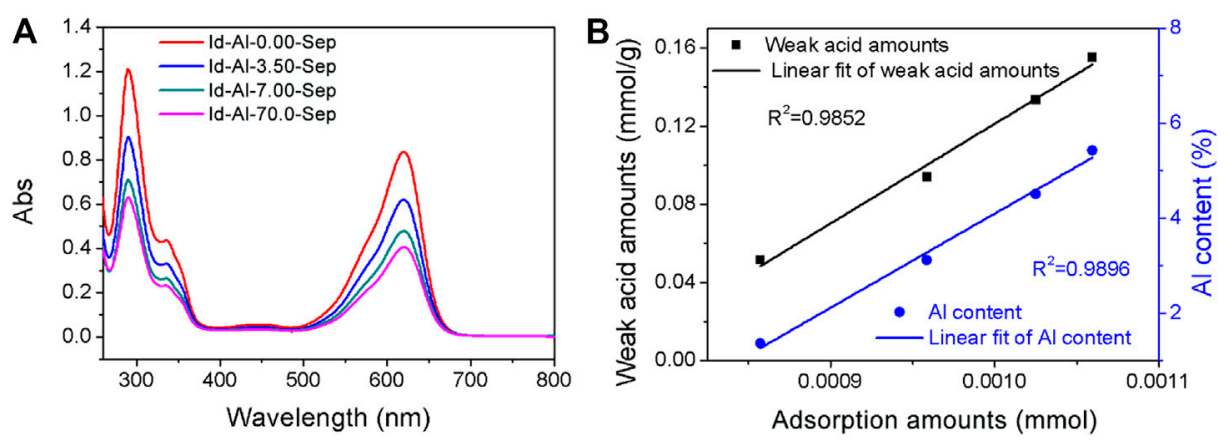

FIGURE 8 | (A) The UV-Vis spectra of supernatant of composite pigments desorbed in DMSO. (B) Linear correlation between the amount of weak acid, Al content in Al-Sep, and the adsorption amount of Id in composite pigment desorbed by DMSO.

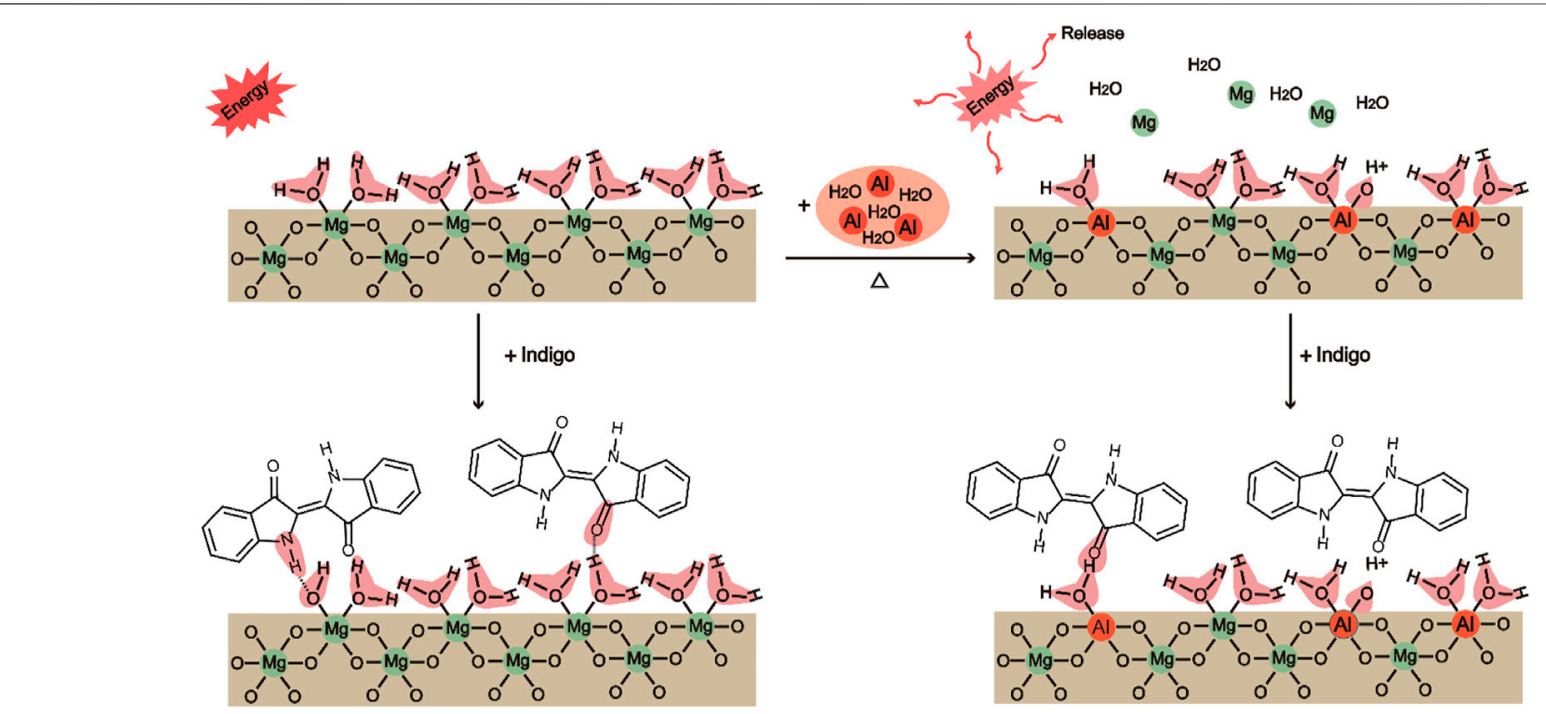

FIGURE 9 | The mechanism of the substitution of $\mathrm{Al}^{3+}$ for $\mathrm{Mg}^{2+}$ located at the octahedron in sepiolite and the bonding of Sep, Al-Sep with Id (executed in (200) plane). 

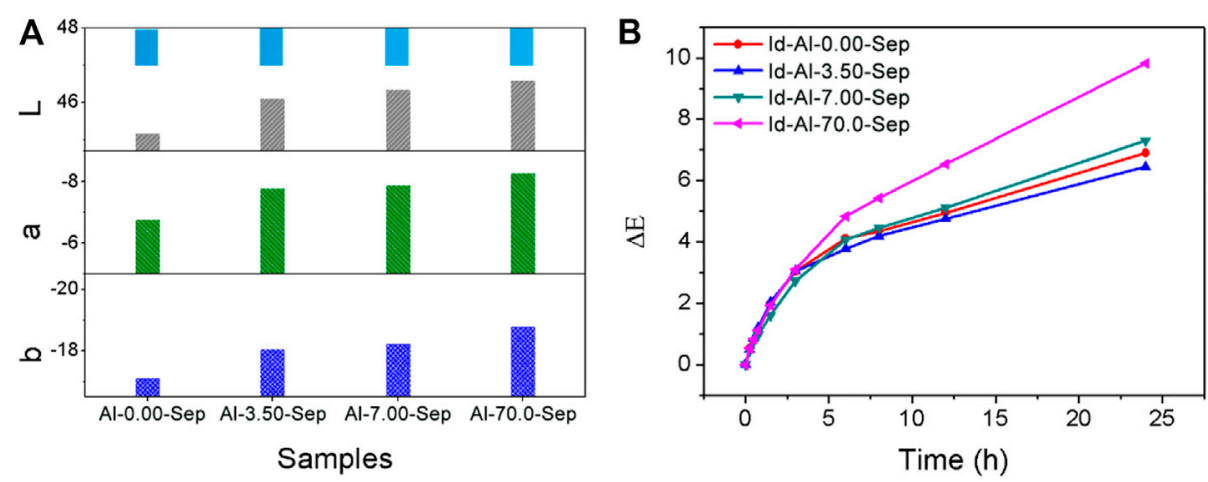

FIGURE 10 | (A) The chromaticity of the composite pigments. (B) The $\Delta \mathrm{E}$ curves of composite pigments at different irradiation times.

results of specific surface area, the possibility that the channels in Al-Sep bound the Id molecule to enhance the bonding has been eliminated. By comparison, a linear correlation is found between the $\mathrm{Al}$ content of Al-Sep and the adsorption amount of Id in composite pigment desorbed by DMSO. Furthermore, weak acid amount and adsorption amount of Id displayed a similar correlation (Figure $\mathbf{8 B}$ ). The general trend is similar to the result of previous studies (Ramírez et al., 2011).

Weak acid sites consist of $\mathrm{Si}-\mathrm{OH}, \mathrm{H}_{3} \mathrm{O}^{+}$, and $\mathrm{Al}-\mathrm{OH}_{2}$. $\mathrm{Al}$ modification can enhance the bonding strength between Id and Al-Sep, as the substitution of $\mathrm{Al}^{3+}$ mainly occurs with $\mathrm{Mg}^{2+}$ in the octahedron, causing the increase of $\mathrm{Al}-\mathrm{OH}_{2}$ at the edge of the octahedron, and $\mathrm{Al}^{3+}$ has a higher electronegativity than $\mathrm{Mg}^{2+}$ and has a higher polarization of coordinated water, resulting in a stronger combination between $\mathrm{C}=\mathrm{O}$ and $\mathrm{N}-\mathrm{H}$ in $\mathrm{Id}$ and $\mathrm{Al}-\mathrm{OH}_{2}$ in Al-Sep, and the mechanism is shown in Figure 9.

Combining the results of FTIR and adsorption amount of Id in composite pigment treated by DMSO, Id bonds with sepiolite through hydrogen bonds between $\mathrm{C}=\mathrm{O}$ and $\mathrm{N}-\mathrm{H}$ in Id and Si$\mathrm{OH}, \mathrm{H}_{3} \mathrm{O}^{+}, \mathrm{Mg}-\mathrm{OH}_{2}$, and $\mathrm{Al}-\mathrm{OH}_{2}$ in Al-Sep, which is consistent with the result of the previous literature (Zhuang et al., 2019). Among them, the bond energy formed by $\mathrm{Al}-\mathrm{OH}_{2}$ and Id is higher than that of $\mathrm{Mg}-\mathrm{OH}_{2}$. Al modification can increase the bonding strength of Id and Al-Sep by the substitution of $\mathrm{Al}^{3+}$ for $\mathrm{Mg}^{2+}$ in the octahedron.

\section{The Chromaticity and Weather Resistance of Composite Pigments \\ Chromaticity}

The chromaticity of Id-Al-Sep composite pigments is presented in Figure 10A. The absolute value of $\mathrm{L}$, $\mathrm{a}$, and $\mathrm{b}$ increases as the dosage of $\mathrm{AlCl}_{3}$ rises, indicating a more vivid color of composite pigments as the bonding strength between Id and sepiolite increases. Increasing the bonding strength between Id and sepiolite is an effective way to improve the chromaticity of composite pigments.

\section{Weather Resistance}

$\Delta \mathrm{E}$ results of composite pigments were measured and calculated after UV irradiation at different times during $24 \mathrm{~h}$ (Figure 10B). A smaller $\Delta \mathrm{E}$ performs better weather resistance. Obviously, the weather resistance of composite pigments is as follows: Id-Al3.50-Sep > Id-Al-0.00-Sep > Id-7.00-Sep > Id-70.0-Sep shows a positive correlation with the acid amounts in Al-Sep. Intramolecular proton transfer between $\mathrm{C}=\mathrm{O}$ and $\mathrm{N}-\mathrm{H}$ in the Id molecule is the main pathway for Id to decolor under UV irradiation (Rondão et al., 2010). The acid in Al-Sep will promote this proton transfer in Id under UV irradiation and promotes the fading rate of Id and reduces the weather resistance of composite pigments.

In summary, $\mathrm{Al}$ modification can increase the amount of weak acid $\mathrm{Al}-\mathrm{OH}_{2}$ in sepiolite. The $\mathrm{Al}-\mathrm{OH}_{2}$ enhances the combination of sepiolite and indigo. For indigo, the acid in Al-Sep can brighten the color and accelerate the fading of composite pigments. This phenomenon originates from the special structure of indigo, and there may be different results in composite pigments prepared by other dyes.

\section{CONCLUSION}

In this study, $\mathrm{AlCl}_{3}$ was used to modify sepiolite. The substitution of $\mathrm{Al}^{3+}$ mainly occurs with $\mathrm{Mg}^{2+}$ located at the edge and section of the octahedron in sepiolite lattice and the substitution amount increases with the increase in the dosage of $\mathrm{AlCl}_{3}$, since the substitution can reduce the energy of the system. The absolute value of zeta potential and specific surface area of sepiolite decreases, while the solid acidity of sepiolite increases as the dosage of $\mathrm{AlCl}_{3}$ rises. $\mathrm{Al}$ modification can enhance the bonding between indigo and sepiolite by increasing the amount of weak acid $\mathrm{Al}-\mathrm{OH}_{2}$ through the substitution of $\mathrm{Al}^{3+}$ for $\mathrm{Mg}^{2+}$ located at the octahedron of sepiolite lattice. The electronegativity of $\mathrm{Al}^{3+}$ is greater than that of $\mathrm{Mg}^{2+}$, and thus, indigo can form a stronger bonding with $\mathrm{Al}-\mathrm{OH}_{2}$ than that with $\mathrm{Mg}-\mathrm{OH}_{2}$. Enhancing the bonding strength between indigo and sepiolite can brighten the composite pigment. The acid in sepiolite will provide a pathway to decolor by promoting the intramolecular proton transfer in the Id molecule, resulting in worse weather resistance. This conclusion is for indigo, and the protective effect of $\mathrm{Al}$ modification on other dyes needs further discussion.

The solid acidity and basicity of sepiolite can be regulated by changing the content and position of $\mathrm{Al}$, and the catalytic activity 
and adsorption performance of sepiolite will be adjusted, accordingly widening the application of sepiolite in the fields of catalysis and adsorption.

\section{DATA AVAILABILITY STATEMENT}

The original contributions presented in the study are included in the article/supplementary material; further inquiries can be directed to the corresponding author.

\section{AUTHOR CONTRIBUTIONS}

HC designed experimental plans, performed main experimental work, analyzed and discussed results, and wrote the manuscript. JG assisted in the design of the scheme, performed the main experimental work, analyzed and discussed the results, and participated in the manuscript writing. ZZ proposed the themes, ideas, and content of the manuscript research work, guided the design of the research plan, the analysis, and discussion of problems, and guided the writing and revision of the manuscript. RJ assisted in literature review and manuscript sorting. JYZ participated in

\section{REFERENCES}

Arnold, D. E., Bohor, B. F., Neff, H., Feinman, G. M., Williams, P. R., Dussubieux, L., et al. (2012). The First Direct Evidence of Pre-columbian Sources of Palygorskite for Maya Blue. J. Archaeological Sci. 39 (7), 2252-2260. doi:10.1016/j.jas.2012.02.036

Aslya, E., Harrane, A., and Belbachir, M. (2016). Polymerization of DL-Lactide Induced by Protonated Montmorillonite clay as a Solid Catalyst: Mechanism Study. Mat. Res. 19 (1), 132-137. doi:10.1590/1980-5373-mr-2015-0322

Bu, H., Yuan, P., Liu, H., Liu, D., Liu, J., He, H., et al. (2017). Effects of Complexation between Organic Matter (OM) and clay mineral on OM Pyrolysis. Geochimica et Cosmochimica Acta 212, 1-15. doi:10.1016/j.gca.2017.04.045

Busca, G. (1999). The Surface Acidity of Solid Oxides and its Characterization by IR Spectroscopic Methods. An Attempt at Systematization. Phys. Chem. Chem. Phys. 1 (5), 723-736. doi:10.1039/a808366e

Buti, D., Domenici, D., Grazia, C., Ostapkowicz, J., Watts, S., Romani, A., et al. (2018). Further Insight into Mesoamerican Paint Technology: Unveiling the Colour Palette of the Pre-columbian Codex Fejérváry-Mayer by Means of Noninvasive Analysis. Archaeometry 60 (4), 797-814. doi:10.1111/arcm.12341

Caillerie, J. B. E., and Fripiat, J. J. (1992). Al Modified Sepiolite as Catalyst or Catalyst Support. Catal. Today 14 (2), 125-140.

Chen, H., Zhang, Z., Zhuang, G., and Jiang, R. (2019). A New Method to Prepare 'Maya Red' Pigment from Sepiolite and Basic Red 46. Appl. Clay Sci. 174, 38-46. doi:10.1016/j.clay.2019.03.023

Chiari, G., Giustetto, R., Druzik, J., Doehne, E., and Ricchiardi, G. (2008). Precolumbian Nanotechnology: Reconciling the Mysteries of the Maya Blue Pigment. Appl. Phys. A 90 (1), 3-7. doi:10.1007/s00339-007-4287-z

Corma, A., Fornes, V., and Mifsud, A. (1991). Aluminum-Exchanged Sepiolite as a Component of Fluid Cracking Catalysts. Washington, DC: American Chemical Society.

Corma, A., and Martín-Aranda, R. M. (1993). Application of Solid Base Catalysts in the Preparation of Prepolymers by Condensation of Ketones and Malononitrile. Appl. Catal. A: Gen. 105 (2), 271-279. doi:10.1016/0926$860 x(93) 80252-1$

Corma, A., and Perez-Pariente, J. (1987). Catalytic Activity of Modified Silicates: I. Dehydration of Ethanol Catalysed by Acidic Sepiolite. Clay miner. 22 (4), 423-433. doi:10.1180/claymin.1987.022.4.06 some experimental work. JCZ guided experimental work and manuscript revision.

\section{FUNDING}

The research and publication fees are supported by the National Natural Science Foundation of China with the project name of Key Parameter Test and Intelligent Evaluation System of Gas-bearing Shale (award number: 41927801). The research fees are supported by Fundamental Research Funds for Central Universities from the Ministry of Education with the project name of Exploration on the preparation process of Maya-like blue pigment (award number: 2652018319)

\section{ACKNOWLEDGMENTS}

This work was financially supported by the Key Parameter Test and Intelligent Evaluation System of Gas-bearing Shale from the National Natural Science Foundation (no. 41927801) and Exploration on the preparation process of Maya-like blue pigment from the Fundamental Research Funds for Central Universities (China) (no. 2652018319).

Doménech-Carbó, A., Doménech-Carbó, M. T., Vidal-Lorenzo, C., Vázquez de Agredos-Pascual, M. L., Osete-Cortina, L., and Valle-Algarra, F. M. (2014). Discovery of Indigoid-Containing clay Pellets from La Blanca: Significance with Regard to the Preparation and Use of Maya Blue. J. archaeological Sci. 41, 147-155. doi:10.1016/j.jas.2013.08.007

Gettens, R. J. (1962). Maya Blue: an Unsolved Problem in Ancient Pigments. Am. Antiquity 2 (1), 557-564. doi:10.2307/277679

Giulieri, F., Ovarlez, S., and Chaze, A. M. (2012). Indigo/sepiolite Nanohybrids: Stability of Natural Pigments Inspired by Maya Blue. Int. J. nanotechnology 9 (37), 605-617. doi:10.1504/IJNT.2012.045334

Giustetto, R., Wahyudi, O., and Corazzari, I. (2011). Chemical Stability and Dehydration Behavior of a Sepiolite/indigo Maya Blue Pigment. Appl. Clay Sci. 52 (1-2), 41-50. doi:10.1016/j.clay.2011.01.027

Giustetto, R., Levy, D., and Chiari, G. (2006). Crystal Structure Refinement of Maya Blue Pigment Prepared with Deuterated Indigo, Using Neutron Powder Diffraction. European. J. Minerol. 18 (5), 629-640. doi:10.1127/0935-1221/ 2006/0018-0629

Giustetto, R., Llabrés i Xamena, F. X., Ricchiardi, G., Bordiga, S., Damin, A., Gobetto, R., et al. (2005). Maya Blue: A Computational and Spectroscopic Study. J. Phys. Chem. B 109 (41), 19360-19368. doi:10.1021/ jp048587h

Grazia, C., Buti, D., Amat, A., Rosi, F., Romani, A., and Domenici, D. (2020). Shades of Blue: Non-invasive Spectroscopic Investigations of Maya Blue Pigments. From Laboratory Mock-Ups to Mesoamerican Codices[J]. Heritage Sci. 8 (1), 1-20. doi:10.1186/s40494-019-0345-z

Hair, M. L., and Hertl, W. (1970). Acidity of Surface Hydroxyl Groups. J. Phys. Chem. 74 (1), 91-94. doi:10.1021/j100696a016

Heller-Kallai, L. (2006). Chapter 7.2 Thermally Modified Clay Minerals. Dev. clay Sci. 1, 289-308. doi:10.1016/s1572-4352(05)01009-3

Hu, C., Yu, J. C., Hao, Z., and Wong, P. K. (2003). Effects of Acidity and Inorganic Ions on the Photocatalytic Degradation of Different Azo Dyes. Appl. Catal. B: Environ. 46 (1), 35-47. doi:10.1016/s0926-3373(03)00139-5

Jha, A., Garade, A. C., Shirai, M., and Rode, C. V. (2013). Metal Cation-Exchanged Montmorillonite clay as Catalysts for Hydroxyalkylation Reaction. Appl. clay Sci. 74, 141-146. doi:10.1016/j.clay.2012.10.005

José-Yacamán, M., Rendón, L., Arenas, J., and Serra Puche, M. C. (1996). Maya Blue Paint: An Ancient Nanostructured Material. Science 273 (5272), 223-225. doi:10.1126/science.273.5272.223 
Kaufhold, S., Stanjek, H., Penner, D., and Dohrmann, R. (2011). The Acidity of Surface Groups of Dioctahedral Smectites. Clay miner. 46 (4), 583-592. doi:10.1180/claymin.2011.046.4.583

Kohno, Y., Tsubota, S., Shibata, Y., et al. (2008). Enhancement of the Photostability of Flavylium Dye Adsorbed on Mesoporous Silicate J. Microporous Mesoporous Materials 116 (1-3), 70-76. doi:10.1016/j.micromeso.2008.03.014

Komarneni, S., Fyfe, C. A., and Kennedy, G. J. (1986). Detection of Nonequivalent Si Sites in Sepiolite and Palygorskite by Solid-State 29Si Magic Angle SpinningNuclear Magnetic Resonance. Clays and Clay Minerals 34 (1), 99-102. doi:10.1346/ccmn.1986.0340113

Lazarevic, S., Jankovic-Castvan, I., and Onjia, A. (2011). Surface Characterization of Iron-Modified Sepiolite by Inverse Gas Chromatography. Ind. Eng. Chem. Res. 50 (20), 11467-11475. doi:10.1021/ie200595n

Liao, L., and Xia, Z. (2013). Crystal Chemistry and Crystal Physics. Beijing, China: Science Press.

Liu, D., Yuan, P., Liu, H., Cai, J., Qin, Z., Tan, D., et al. (2011). Influence of Heating on the Solid Acidity of Montmorillonite: A Combined Study by DRIFT and Hammett Indicators. Appl. Clay Sci. 52 (4), 358-363. doi:10.1016/j.clay.2011.03.016

Liu, D., Yuan, P., Liu, H., Cai, J., Tan, D., He, H., et al. (2013). Quantitative Characterization of the Solid Acidity of Montmorillonite Using Combined FTIR and TPD Based on the NH3 Adsorption System. Appl. Clay Sci. 80-81, 407-412. doi:10.1016/j.clay.2013.07.006

Liu, H., Yuan, P., Qin, Z., Liu, D., Tan, D., Zhu, J., et al. (2013). Thermal Degradation of Organic Matter in the Interlayer clay-organic Complex: A TG-FTIR Study on a Montmorillonite/12-Aminolauric Acid System. Appl. clay Sci. 80-81, 398-406. doi:10.1016/j.clay.2013.07.005

Niwa, M., Katada, N., and Okumura, K. (2010). Characterization and Design of Zeolite Catalysts: Solid Acidity, Shape Selectivity and Loading properties. Berlin, Germany: Springer Science \& Business Media. doi:10.1007/978-3-642-12620-8

Novikova, L., Belchinskaya, L., and Roessner, F. (2013). Characterization of Surface Acidity and Catalytic Ability of Natural clay Minerals by Means of Test Catalytic Reaction. Acta Geodynamica et Geomaterialia 10 (4), 172. doi:10.13168/AGG.2013.0048

Ouellet-Plamondon, C., Aranda, P., Favier, A., Habert, G., van Damme, H., and Ruiz-Hitzky, E. (2015). The Maya Blue Nanostructured Material Concept Applied to Colouring Geopolymers. RSC Adv. 5 (120), 98834-98841. doi:10.1039/c5ra14076e

Ovarlez, S., Giulieri, F., Delamare, F., Sbirrazzuoli, N., and Chaze, A.-M. (2011). Indigo-sepiolite Nanohybrids: Temperature-dependent Synthesis of Two Complexes and Comparison with Indigo-Palygorskite Systems. Microporous Mesoporous Mater. 142 (1), 371-380. doi:10.1016/j.micromeso.2010.12.025

Phukan, A., Borah, S. J., Bordoloi, P., Sharma, K., Borah, B. J., Sarmah, P. P., et al. (2017). An Efficient and Robust Heterogeneous Mesoporous Montmorillonite clay Catalyst for the Biginelli Type Reactions. Adv. Powder Techn. 28 (6), 1585-1592. doi:10.1016/j.apt.2017.03.030

Polisi, M., Arletti, R., Morandi, S., Fabbiani, M., Martra, G., Quartieri, S., et al. (2018). Zeolite/dye Hybrid Composites: Organization of Photoactive Azobenzene Molecules inside AlPO4-5. Microporous Mesoporous Mater. 268, 25-30. doi:10.1016/j.micromeso.2018.03.038

Pushpaletha, P., and Lalithambika, M. (2011). Modified Attapulgite: An Efficient Solid Acid Catalyst for Acetylation of Alcohols Using Acetic Acid. Appl. Clay Sci. 51 (4), 424-430. doi:10.1016/j.clay.2010.12.033
Ramírez, A., Sifuentes, C., Manciu, F. S., Komarneni, S., Pannell, K. H., Chianelli, R. R., et al. (2011). The Effect of Si/Al Ratio and Moisture on an Organic/inorganic Hybrid Material: thioindigo/Montmorillonite. Appl. clay Sci. 51 (1-2), 61-67. doi:10.1016/j.clay.2010.11.002

Rondão, R., Seixas de Melo, J. S., Bonifácio, V. D. B., and Melo, M. J. (2010). Dehydroindigo, the Forgotten Indigo and its Contribution to the Color of Maya Blue. J. Phys. Chem. A. 114 (4), 1699-1708. doi:10.1021/jp907718k

Sánchez Del Río, M., Martinetto, P., Reyes-Valerio, C., Dooryhée, E., and Suárez, M. (2006). Synthesis and Acid Resistance of Maya Blue Pigment*. Archaeometry 48 (1), 115-130. doi:10.1111/j.1475-4754.2006.00246.x

Spange, S., Prause, S., Vilsmeier, E., and Thiel, W. R. (2005). Probing Surface Basicity of Solid Acids with an Aminobenzodifurandione Dye as the Solvatochromic Probe. J. Phys. Chem. B 109 (15), 7280-7289. doi:10.1021/ jp040521z

Tazi, S., Rotenberg, B., Salanne, M., Sprik, M., and Sulpizi, M. (2012). Absolute Acidity of clay Edge Sites from Ab-Initio Simulations. Geochimica et Cosmochimica Acta 94, 1-11. doi:10.1016/j.gca.2012.07.010

Van Olphen, H. (1966). Maya Blue: A Clay-Organic Pigment? Science 154 (3749), 645-646. doi:10.1126/science.154.3749.645

Vandenabeele, P., Bodé, S., Alonso, A., and Moens, L. (2005). Raman Spectroscopic Analysis of the Maya wall Paintings in Ek'Balam, Mexico. Spectrochimica Acta A: Mol. Biomol. Spectrosc. 61 (10), 2349-2356. doi:10.1016/j.saa.2005.02.034

Wang, X. L., Zou, G. W., and Bi, S. P. (2000). Advances in Determination of Aluminum in Environmental and Biological Materials by Al 27 Nuclear Magnetic Resonance Spectroscopy. Chin. J. Inorg. Chem. 16 (4), 548-560. doi:10.1103/PhysRevLett.60.658

Zheng, S.-Q., Han, Y., Huang, X.-H., Dai, Y.-L., Qian, D., Zhang, J.-C., et al. (2010). Acid and Aluminium Modification of Sepiolite and its Application in FCC Catalysis. Clay miner. 45 (1), 15-22. doi:10.1180/claymin.2010.045.1.15

Zhuang, G., Jaber, M., Rodrigues, F., Rigaud, B., Walter, P., and Zhang, Z. (2019). A New Durable Pigment with Hydrophobic Surface Based on Natural Nanotubes and Indigo: Interactions and Stability. J. Colloid Interf. Sci. 552, 204-217. doi:10.1016/j.jcis.2019.04.072

Conflict of Interest: The authors declare that the research was conducted in the absence of any commercial or financial relationships that could be construed as a potential conflict of interest.

Publisher's Note: All claims expressed in this article are solely those of the authors and do not necessarily represent those of their affiliated organizations, or those of the publisher, the editors, and the reviewers. Any product that may be evaluated in this article, or claim that may be made by its manufacturer, is not guaranteed or endorsed by the publisher.

Copyright (C) 2021 Chen, Geng, Zhang, Jiang, Zhai and Zhang. This is an open-access article distributed under the terms of the Creative Commons Attribution License (CC $B Y)$. The use, distribution or reproduction in other forums is permitted, provided the original author(s) and the copyright owner(s) are credited and that the original publication in this journal is cited, in accordance with accepted academic practice. No use, distribution or reproduction is permitted which does not comply with these terms. 